\title{
UTILIZAÇÃO DE ENZIMAS LIPOLÍTICAS DE ORIGEM FÚNGICA NA PRODUÇÃO DE BIODIESEL A PARTIR DE ÓLEO DE COZINHA USADO
}

\author{
L. G. S PAULA ${ }^{1}$, G. G. PEREIRA ${ }^{1}$ (Orientador), F. P. CASCIATORI ${ }^{2}$ \\ E-mail: luispaula3@gmail.com \\ ${ }^{1}$ Universidade Federal de São Carlos, Centro de Ciências da Natureza \\ ${ }^{2}$ Universidade Federal de São Carlos, Departamento de Engenharia Química
}

\begin{abstract}
RESUMO - O presente trabalho teve como objetivo avaliar a aplicação de lipases na síntese de biodiesel a partir de óleo vegetal residual. Inicialmente, o óleo foi submetido a diferentes pré-tratamentos, a saber in natura (somente filtrado, IN), degomado (D) e degomado e desumidificado (DD). Em seguida, conduziu-se a reação de transesterificação, variando-se a fração de enzima no meio reacional, a proporção óleo:etanol e a presença ou ausência de hexano (solvente orgânico) no meio reacional para cada pré-tratamento. O tempo e a temperatura de reação foram mantidos constantes para os três grupos de óleo. Uma metodologia analítica convencional foi empregada nestes testes iniciais para triagem da melhor condição para obtenção de biodiesel em substituição à análise cromatográfica por questões de redução de custo analítico. Os resultados obtidos até o momento demonstraram que o pré-tratamento dos óleos, não foi eficiente para reduzir o índice de acidez, o que poderia favorecer a atuação da enzima. Em relação ao efeito das variáveis no rendimento de biodiesel, os resultados indicam que maior quantidade de enzima e ausência de hexano no meio reacional propiciaram maiores rendimentos, mas novos testes deverão ser realizados para confirmação estatística do efeito dessas variáveis. Os testes de qualidade do biodiesel obtido demonstraram que o mesmo não se enquadrou em alguns parâmetros analisados estabelecidos pela legislação.
\end{abstract}

\section{INTRODUÇÃO}

Nas décadas de 30 e 40, óleos vegetais eram utilizados em motores em caso de falta de combustíveis derivados do petróleo. No entanto, seu uso direto era insatisfatório devido aos seus elevados índices de acidez e à deposição de compostos de carbono. Haja vista a limitação das reservas de combustíveis fósseis e o agravamento do aquecimento global devido à emissão excessiva de gases do efeito estufa, os combustíveis alternativos vêm se destacando, dentre os quais o biodiesel aparece como exemplo de energia renovável e sustentável.

O biodiesel é definido como o derivado mono-alquil-éster de ácidos graxos de cadeia longa, proveniente de fontes renováveis como óleos vegetais, gorduras animais e até mesmo óleo de cozinha usado (HU et al., 2004). Além de sua matéria-prima ser alvo de pesquisas, há também a busca pelo desenvolvimento de derivados de óleos vegetais que se aproximem das características dos derivados do petróleo, sobretudo em termos de compatibilidade energética. 
Em linhas gerais, o processo de obtenção do biodiesel consiste em reações de transesterificação de triacilgliceróis presentes em óleos vegetais com metanol ou etanol na presença de catalisadores. O uso de etanol (derivado da cana de açúcar e atóxico) ao invés do metanol (derivado do petróleo e tóxico) associado à catálise enzimática (empregando lipase obtida por fermentação sólida) ao invés da catálise química de óleo de cozinha usado ao invés de óleos virgens mostra-se como uma das rotas mais amigáveis, do ponto de vista ambiental, para se produzir biodiesel, uma vez que propicia uma cadeia de produção suprida por insumos renováveis e rejeitos agroindustriais em todas as suas etapas.

Neste contexto, o objetivo geral do presente projeto de iniciação científica é utilizar lipases para obtenção de biodiesel a partir de óleo de cozinha usado, visando seu uso futuro nos maquinários agrícolas da fazenda Lagoa do Sino da UFSCar. Os objetivos específicos do projeto incluem reutilizar óleo de cozinha gerado pela comunidade universitária da UFSCar campus Lagoa do Sino; realizar a transesterificação do óleo empregando etanol e enzima lipolítica oriunda do cultivo de fungo em estado sólido; efetuar análises físico-químicas para avaliar a qualidade do biodiesel produzido.

\section{MATERIAIS E MÉTODOS}

\section{1 Óleo de cozinha residual e pré-tratamentos}

Amostras de óleo vegetal usado foram coletadas junto à comunidade acadêmica do campus Lagoa do Sino da UFSCar e foram homogeneizadas para obtenção de uma amostra representativa. O óleo de cozinha usado, substrato para a obtenção do biodiesel, foi submetido às reações de transesterificação de três formas: (i) in natura (IN), tendo passado somente por filtração, (ii) degomado (D) e (iii) degomado e desumidificado (DD).

A filtração foi conduzida sob vácuo e objetivou remover os resíduos de alimentos presentes no óleo de fritura residual. A degomagem do óleo foi realizada em banho termostático com agitador, adicionando-se $3 \%$ em volume de água no óleo sob agitação constante de $300 \mathrm{rpm}$ por 20 minutos. A separação do óleo degomado da goma (fosfatídeos solubilizados em água) foi conduzida em funil de separação, deixando-se decantar por $24 \mathrm{~h}$ (MORAIS et al., 2007).

Todas as amostras de óleo foram analisadas quanto à acidez, que foi determinada através de método titulométrico, medindo-se a quantidade de hidróxido de potássio $(\mathrm{KOH}) 1$ M necessária para neutralizar $1 \mathrm{~g}$ de óleo. Tais análises foram realizadas em triplicata.

\subsection{Reações de transesterificação para obtenção de biodiesel}

As reações de transesterificação para síntese de biodiesel foram realizadas em frascos de $50 \mathrm{~mL}$ em uma incubadora com agitador orbital a $120 \mathrm{rpm}$. As variáveis independentes nos primeiros ensaios de obtenção de biodiesel foram as seguintes: razão óleo:etanol, a concentração de extrato enzimático liofilizado (produzido pelo fungo termofílico Rhizomиcor pusillus) e a presença ou ausência de solvente orgânico (hexano). A variável resposta foi o volume de biodiesel obtido. Os níveis dos fatores foram os seguintes: razão óleo:álcool 3:1 e 3:2, razão óleo:hexano 3:0 e 3:1 e fração mássica de enzima 0,33 e $0,17 \% \mathrm{~m} / \mathrm{v}$. Todos os ensaios foram realizados em duplicata, tanto para óleo in natura quanto para o óleo degomado 


\section{Congresso Brasileiro de Engenharia Química \\ em Iniciação Científica \\ UFSCar - São Carlos - SP \\ 16 a 19 de Julho de 2017}

CONGRESSO BRASILEIRO DE ENGENHARIA

e degomado e desumidificado. Nestes primeiros testes, o tempo e a temperatura de reação foram fixos em, respectivamente, 24 horas e $50^{\circ} \mathrm{C}$.

Após a reação de transesterificação, o volume de biodiesel obtido foi quantificado de acordo com a metodologia descrita por Geris et al. (2007), que consiste na transferência da mistura reacional para um funil de separação para a decantação e separação das fases: fase superior, contendo biodiesel, e fase inferior, composta de glicerol, sabões, enzimas, álcool e hexano. O tempo de espera para separação das fases foi de 24 horas. Após o tempo de espera, recolheu-se a fase inferior numa proveta para medir-se o volume obtido, bem como a fase superior. Em seguida, voltou-se a fase superior (contendo o biodiesel) para o funil de separação, para realizar a lavagem e a desumidificação do biocombustível, o que foi feito em três etapas, a saber: lavagem inicial com o mesmo volume de solução aquosa de ácido clorídrico a $0,5 \%$ (v/v), deixando-se em repouso por 30 minutos; segunda lavagem com o mesmo volume de solução saturada de $\mathrm{NaCl}$, deixando-se em repouso por 30 minutos; e lavagem final com o mesmo volume de água destilada, deixando-se em repouso por mais 30 minutos. Por fim, para remoção dos traços de umidade, o biodiesel foi filtrado utilizando-se sulfato de sódio anidro e transferido para uma proveta para medição do volume final, sendo que o biodiesel apresentou-se como um líquido límpido de cor amarela.

\subsection{Análises físico-químicas do biodiesel obtido}

O biodiesel obtido na condição de reação que propiciou maior rendimento em volume foi submetido a algumas análises físico-químicas básicas para avaliação de sua qualidade e de seu potencial para uso em maquinários agrícolas do campus Lagoa do Sino da UFSCar.

Foi determinada a massa específica do biodiesel a $20^{\circ} \mathrm{C}$ através da relação massa por volume. Para determinação da corrosividade do biodiesel ao cobre, utilizou-se um pedaço de fio de cobre polido, que foi submerso no biocombustível por 3 horas a $50{ }^{\circ} \mathrm{C}$, após o que foi lavado e comparado a um pedaço de fio virgem para avaliação do grau de corrosão. A determinação dos resíduos de carbono foi feita por meio de evaporação e queima da amostra, seguidas da pesagem do resíduo. A concentração de contaminantes inorgânicos foi avaliada com base no teor de cinzas sulfatadas, que foram determinadas por queima da amostra na presença de ácido sulfúrico. O índice de acidez da amostra foi determinado por titulação com solução de $\mathrm{KOH} 1 \mathrm{M}$, tendo fenolftaleína como indicador. Os parâmetros de qualidade determinados foram comparados aos padrões estabelecidos pela legislação brasileira.

\section{RESULTADOS E DISCUSSÃO}

\subsection{Pré-tratamento}

Na Tabela 1 estão apresentados os resultados referentes à acidez dos óleos in natura (IN), degomado (D) e degomado e desumidificado (DD).

Tabela 1 - Acidez dos óleos IN, D e DD.

\begin{tabular}{cccc}
\hline Amostra & In Natura (IN) & Degomado (D) & Degomado e desumidificado (DD) \\
\hline $\begin{array}{c}\text { Acidez (mg } \\
\text { KOH/g) }\end{array}$ & $19,2( \pm 2,7)$ & $14,1( \pm 0,9)$ & $18,7( \pm 0,2)$ \\
\hline
\end{tabular}


A partir da Tabela 1 é possível observar que os pré-tratamentos realizados não foram eficientes em reduzir a acidez do óleo vegetal residual. $\mathrm{O}$ óleo de fritura naturalmente apresenta alto valor de acidez, uma vez que as altas temperaturas do processo e o contato com a água proveniente do alimento favorecem a decomposição dos triacilgliceróis. Dentre os prétratamentos, a degomagem foi a que apresentou melhores resultados, já que acidez reduziu de 19,2 para $14,1 \mathrm{mg} \mathrm{KOH} / \mathrm{g}$.

Altos índices de acidez têm um efeito bastante negativo sobre a qualidade do óleo, a ponto de torná-lo impróprio até mesmo para fins carburantes. É recomendável que óleos destinados à produção de biodiesel apresentem índices de acidez inferiores a $1 \%$, para que o combustível obtido não venha a causar danos ao motor, tais como ação corrosiva sobre os componentes metálicos das tubulações e da carcaça (VIEIRA et al., 2009). Além disso, a acidez dos óleos pode catalisar reações intermoleculares dos triacilgliceróis, ao mesmo tempo em que afeta a estabilidade térmica do combustível na câmara de combustão.

Apesar da elevada acidez, os óleos foram submetidos a reação de transesterificação com o intuito de avaliar se as lipases seriam capazes de originar ésteres monoalquílicos a partir dos ácidos graxos livres.

\subsection{Efeito das variáveis analisadas sobre o rendimento de biodiesel}

Na Tabela 2 estão apresentados os resultados dos ensaios de transesterificação dos óleos in natura (IN) e degomado (D) para 24 horas de reação a $50{ }^{\circ} \mathrm{C}$. Não foi detectada produção de biodiesel a partir do óleo degomado e desumidificado (DD).

Tabela 2 - Resultados dos testes de transesterificação para obtenção de biodiesel.

\begin{tabular}{|c|c|c|c|c|c|c|c|}
\hline \multicolumn{8}{|c|}{ In natura (IN)* } \\
\hline Ensaio & $\begin{array}{l}\text { Óleo } \\
(\mathrm{mL})\end{array}$ & $\begin{array}{l}\text { Etanol } \\
(\mathrm{mL})\end{array}$ & $\begin{array}{l}\text { Hexano } \\
(\mathrm{mL})\end{array}$ & $\begin{array}{l}\text { Enzima } \\
(\mathrm{g})\end{array}$ & $\begin{array}{l}\text { Fração saponificável } \\
(\mathrm{mL})\end{array}$ & $\begin{array}{l}\text { Biodiesel } \\
\text { bruto }(\mathrm{mL})\end{array}$ & $\begin{array}{l}\text { Biodiesel } \\
\text { puro }(\mathrm{mL})\end{array}$ \\
\hline 1 & 18 & 6 & 6 & 0,1 & 10,0 & 15,0 & 3,5 \\
\hline 2 & 18 & 12 & 0 & 0,1 & 4,8 & 15,2 & 9,9 \\
\hline 3 & 18 & 6 & 6 & 0,05 & & $\mathrm{ND}^{* *}$ & \\
\hline 4 & 18 & 12 & 0 & 0,05 & & $\mathrm{ND}^{* *}$ & \\
\hline \multicolumn{8}{|c|}{ Degomado (D)* } \\
\hline Ensaio & $\begin{array}{l}\text { Óleo } \\
(\mathrm{mL})\end{array}$ & $\begin{array}{c}\text { Etanol } \\
(\mathrm{mL})\end{array}$ & $\begin{array}{c}\text { Hexano } \\
(\mathrm{mL})\end{array}$ & $\begin{array}{l}\text { Enzima } \\
(\mathrm{g})\end{array}$ & $\begin{array}{c}\text { Fração } \\
\text { saponificável } \\
(\mathrm{mL})\end{array}$ & $\begin{array}{l}\text { Biodiesel } \\
\text { bruto }(\mathrm{mL})\end{array}$ & $\begin{array}{l}\text { Biodiesel } \\
\text { puro }(\mathrm{mL})\end{array}$ \\
\hline 1 & 18 & 6 & 6 & 0,1 & & ND** & \\
\hline 2 & 18 & 12 & 0 & 0,1 & & $\mathrm{ND} * *$ & \\
\hline 3 & 18 & 6 & 6 & 0,05 & & $\mathrm{ND} * *$ & \\
\hline 4 & 18 & 12 & 0 & 0,05 & 3,0 & 14,0 & 11,0 \\
\hline
\end{tabular}

* Média; ** Não detectado.

Embora para a maioria dos testes não tenha sido possível detectar a produção de biodiesel através da metodologia analítica empregada, algumas condições experimentais resultaram rendimentos razoáveis de biocombustível, com destaque para o obtido a partir de óleo submetido à degomagem. Observou-se que o óleo in natura levou à obtenção de 
biodiesel mais impuro, uma vez que o seu volume reduziu drasticamente após as lavagens. Os rendimentos observados foram de 12 a $37 \%$ (v/v), valores estes que, embora não sejam tão expressivos quanto os relatados na literatura de catálise química (TAMALAMPUDI et al., 2008; HAMA et al., 2006; BAN et al., 2001), são interessantes, considerando que a via enzimática é mais ambientalmente amigável por não usar produtos químicos tóxicos.

A temperatura é outra variável que tem uma interferência direta na reação de obtenção do biodiesel, sendo um fator que vem sendo estudado, pois o aumento da temperatura da reação diminui a viscosidade de óleos e resulta em maiores taxas de conversão de ésteres monoalquílicos. Entretanto, valores de temperatura acima do nível ótimo diminuem o rendimento da síntese de biodiesel, acelerando as reações de saponificação dos triacilgliceróis e a evaporação do álcool reagente, além de afetar a estabilidade do biocatalisador enzimático, podendo causar a desnaturação da enzima. No entanto, considerando a termoestabilidade da enzima produzida pelo fungo termofílico Rhizomucor pusillus, acredita-se que a temperatura ideal de reação seja igual ou maior que $50{ }^{\circ} \mathrm{C}$, não devendo ter sido a alta temperatura o fator responsável pela não detecção da síntese de biodiesel na maioria das condições experimentais, com destaque para o óleo DD.

Acredita-se que a não detecção da síntese de biodiesel esteja associada a dois fatores experimentais principais: o tipo de incubadora e a metodologia empregada. Com relação à incubadora, que consiste numa câmara termostática de frascos agitados com circulação forçada de ar quente, pode ter ocorrido que álcool e hexano tenham evaporado muito rapidamente, a ponto de a reação de transesterificação ter apenas se iniciado no meio reacional. Em relação à metodologia, percebeu-se que maior tempo de decantação e centrifugação das amostras ajudou na separação de fases, mas o método é subjetivo e não permite afirmar se houve ou não a formação de ésteres etílicos em maior ou menor proporção em cada condição, o que poderia ser determinado mediante análises cromatográficas, a serem realizadas nas etapas seguintes do projeto.

\subsection{Parâmetros de qualidade do biodiesel obtido}

Na Tabela 3, estão apresentados os resultados dos parâmetros de qualidade do biodiesel obtido na reação de transesterificação que proporcionou maior rendimento, que, como supracitado, foi a partir do óleo degomado, na ausência de hexano, razão óleo:álcool 3:2 e teor de enzima $0,17 \%(\mathrm{~m} / \mathrm{v})$.

Tabela 3 - Parâmetros de qualidade do biodiesel obtido.

\begin{tabular}{lcc}
\hline \multicolumn{1}{c}{ Parâmetro } & $\begin{array}{c}\text { Valor } \\
\text { obtido }\end{array}$ & $\begin{array}{c}\text { Valor de referência } \\
\text { (legislação) }\end{array}$ \\
\hline Densidade $\left(\mathrm{kg} / \mathrm{m}^{3}\right)$ & 869,6 & 800 a 900 \\
Resíduo de carbono $(\%)$ & 0,01 & 0,05 \\
Corrosão do cobre $(\mathrm{grau})$ & 5 & 1 \\
Cinzas sulfatadas $(\%)$ & 0,13 & 0,020 \\
Índice de acidez do biodiesel $\left(\mathrm{mg}_{\mathrm{KOH}} / \mathrm{g}\right)$ & 2,34 & 0,50 \\
\hline
\end{tabular}

A partir dos resultados é possível observar que o biodiesel se enquadrou nos limites propostos pela legislação quanto à densidade e resíduo de carbono. Por outro lado, o biodiesel obtido demonstrou uma grande corrosão ao fio de cobre, o que já era esperado dado o alto 
índice de acidez do óleo residual de fritura. Adicionalmente, o teor máximo de cinzas sulfatadas em biodiesel é de $0,020 \%(\mathrm{~m} / \mathrm{m})$, estabelecido pela norma EN 14214. No entanto, o resultado obtido para essa análise passou $0,11 \%$ do permitido por lei, o que pode ter sido decorrente do uso de um pedaço de algodão comum para se tampar o frasco utilizado na reação. E por fim, a acidez do biodiesel obtido foi superior ao limite estabelecido pela legislação, uma vez que a matéria-prima já apresentava altos valores para este parâmetro.

\section{AGRADECIMENTOS}

Os autores agradecem à FAPESP pela bolsa de Iniciação Científica (proc. 2016/09162-1).

\section{REFERÊNCIAS}

HU, J.; DU, Z.; TANG, Z.; MIN, E. Study on the solvent power of new green solvent: biodiesel. Industrial Engineering Chemical Resources, v. 43, p. 7928 - 7931, 2004.

MORAIS, M. M.; PINTO, L. A. A.; ORTIZ, S. C. A.; CREXI, V. T.; SILVA, R. L.; SILVA, J. D. Revista Instituto Adolfo Lutz, v. 60, n. 23, 2001.

VIEIRA, A. C.; VASCONCELOS, V. M.; PEREIRA, D. F.; da SILVA, G. F.; ARANDA, D. A. G. Estudo da separação (goma/óleo) no processo de degomagem. III Simpósio Nacional De Biocombustíveis, Rio de Janeiro - RJ, 2010. 